attractive to private hospital groups than to the pharmaceutical industry, but, as in the United States, there would be scope for mergers and alliances.

In primary care, contracting for services has hardly begun, but it would enable more quality control than in the present system and it would be more open to competition from alternative providers. Moreover, general practitioners will increasingly be looking for alternative ways of financing their premises. Already there are pharmacies in health centres owned by general practitioners: how long before we see general practitioners in premises owned by the private sector, and then the private provider contracting for the services?

With government and health authorities under financial pressure and drug companies and private providers looking for commercial opportunities, increased cooperation is likely between the public and private sectors. To prevent the pharmaceutical industry from becoming overdominant, the
NHS itself must support its providers in their own efforts to develop protocols, integrate care, and improve quality. It also remains to be seen how far drug companies will want to move from provider support to service provision and how adequate will the safeguards be in Britain's managed care for clinical integrity and professional freedom.

MARTIN LAWRENCE Lecturer in general practice

Department of Public Health and Primary Care,

Oxford University,

Radcliffe Infirmary,

Oxford OX2 6HE

TIM WILLIAMS

Merck Sharp, and Dohme,

Hertford Road,

Hoddesdon,

Herts EN13 9BU

\footnotetext{
Macara A. BMA rejects trend towards American style managed care. London: BMA, 1995. (Press release 23 October.)

2 Boston Consulting Group. The promise of disease management. Boston: BCG, 1995.

3 Health Authorities Act 1995.

4 Scandinavian Simvastatin Survival Study Group. Randomised trial of cholesterol lowering in 4,444 patients with coronary heart disease: the Scandinavian simvastatin survival study (4S) Lancet 1994;344:1383-9.

5 Shepherd J, Cobbe SM, Ford I. Prevention of coronary heart disease with pravastatin. $N$ Eng Med 1996;334:1334-5.
}

6 Eckette S. An evolutionary strategy for success in disease management. Scrip 1995 Nov: 9-10.

\footnotetext{
Royal College of General Practitioners. The development and implementation of clinical guidelines. London: RCGP, 1995.

Forrow L, Taylor WC, Arnold RM. Absolutely relative: how research results are summarised can affect treatment decisions. Am F Med 1992;92:121-4.

9 Bucher HC, Weinbacher M, Gyr K. Influence of method of reporting study results on decision of physicians to prescribe drugs to lower cholesterol concentration. BMF 1994;309:761-4.

10 Department of Health. Changing childbirth. Part 1: report of the Expert Materniry Group. London: HMSO, 1993.

11 NHS Executive. Commercial approaches to the NHS regarding disease management packages. Leeds: NHSE, 1994. (EL (94) 94.)

12 NS Executive. Market testing in the NHS: update and future plans. Leeds: NHSE, 1995. (EL (95) 29.)
}

\title{
Physical activity and health
}

\author{
Avoiding the short and miserable life
}

"Of all the causes which conspire to render the life of man short and miserable, none have greater influence than the want of proper exercise."

Recent epidemiological and clinical evidence support this observation by the 18th century Scottish physician Dr William Buchan. Studies suggest causal associations between regular physical activity and reduced rates of coronary heart disease, hypertension, non-insulin dependent diabetes mellitus, osteoporosis, colon cancer, anxiety, and depression. ${ }^{2}$ The most persuasive proof concerns coronary heart disease. People who are regularly active have about half the risk of those who are sedentary. ${ }^{34}$ Unfortunately, in the United States, Britain, and most other developed nations fewer than half of adults are regularly active. ${ }^{5-7}$ An estimated third of deaths from coronary heart disease in the United States (about 160000 deaths per year) are attributable to insufficient physical activity. ${ }^{8}$

In response to the accumulated research and the widespread recognition that physical inactivity is a major public health issue, the United States National Institutes of Health convened a consensus development conference on physical activity and cardiovascular health last December. After two and a half days of scientific presentations and public discussion, a panel of independent scientists, practising physicians, and consumers reaffirmed that physical inactivity is a major risk factor for cardiovascular disease. ${ }^{9}$ They noted that "moderate levels of regular physical activity confer significant health benefits" and that cardiac rehabilitation programmes provide appreciable medical and cost benefits.

The panel recommended that all children and adults should gradually build to 30 minutes of activity of moderate intensity on most, preferably all, days of the week. People who are already that active can achieve greater benefits by increasing either the duration or intensity of activity. The panel purposefully called for "physical activity" rather than "exercise" because most people can incorporate moderate intensity activities into their daily routine. ${ }^{10}$ The panel noted that 30 minutes can be accumulated through segments of at least 10 minutes' duration. Most adults do not need medical testing before starting regular, moderate intensity activity such as brisk walking or gardening, but men over 40 and women over 50 years of age with multiple cardiovascular risk factors who contemplate a programme of vigorous activity, and people with known cardiovascular disease, should consult a physician. ${ }^{9}$

Routine activity patterns are determined by societal and individual factors. The panel noted that medical care providers have a key part to play in informing people about the importance of physical activity, and it recommended that materials be developed to help them. The panel also recommended environmental and policy changes at schools, worksites, and other community sites, such as indoor areas for lunchtime walking; as well as a coordinated national campaign to promote physical activity in the United States. ${ }^{9}$

The panel's recommendations concur with recent statements from voluntary, federal, and academic organisations in the United States ${ }^{211}$ and from the Department of Health in Britain. ${ }^{12}$ However, behind these consensus statements stand two perplexing impediments to widespread and easy promotion of physical activity. One concerns the amount and intensity of activity; the other concerns the difficulty of stimulating a sedentary society to become more active.

The recommended dose of exercise is an accumulated 30 minutes of moderate intensity activity - such as brisk walking, gardening, cycling, or swimming-on most, preferably all, days of the week. ${ }^{2910}$ The recommendation, however, may not be specific enough for people interested in enhancing their activity pattern. Will less than the recommended dose provide any benefit? Will vigorous activity provide greater benefits? These details are important to health care providers who may 
want to know specifically what to recommend, and to members of the public, many of whom want to know how little they can get away with while still reaping the benefits.

Studies suggest that increasing one's activity reduces the risk of coronary heart disease even if the recommended dose is not achieved. There is no apparent threshold, and each increment further reduces the risk. ${ }^{12}$ Among people who are already active, vigorous activity probably adds benefit, but how much and at what risk is uncertain. Injuries, and sudden death, may increase more with intensity than volume. ${ }^{13}$

Developing a more active society will not be easy. Industrialised society systematically excludes physical activity from our daily lives. Even walking, the simplest and most natural of all activities, can require the commitment of a salmon swimming upstream to spawn. Many American communities have few pavements, no cycle paths, inaccessible stairways, inadequate public transport systems, problems with safety on the streets, and stores, schools, and workplaces that are many miles from homes. All of these factors make staying at home or driving cars more attractive than walking or bicycling.

Highly individualised messages will be necessary. Despite their inadequate representation in the research literature, nonwhite men and women of all racial and ethnic groups seem to accrue the same relative benefits from activity as white men. However, attitudes and behaviours are significantly influenced by sex, age, weight, marital status, socioeconomic status,

\footnotetext{
1 Berryman JW. The tradition of the "six things non-natural": exercise and medicine from Hippocrates through Ante-Bellum America. Med Sci Sports Exerc 1989;17:515-59.

2 Pate RR, Pratt M, Blair SN, Haskell WL, Macera CA, Bouchard C, et al. Physical activity and public health: a recommendation from the Centers for Disease Control and Prevention and the American College of Sports Medicine. $\mathscr{F} A M A$ 1995;273:402-7.

3 Powell KE, Thompson PD, Caspersen CJ, Kendrick JS. Physical activity and the incidence of coronary heart disease. Ann Rev Public Health 1987;8:253-87.

4 Berlin JA, Coldiz GA. A meta-analysis of physical activity in the prevention of coronary heart disease. Am ₹ Epidemiol 1990;132:612-28.

5 Caspersen CJ, Merritt RK. Physical activity trends among 26 states, 1986-1990. Med Sci Sports Exerc 1995;27:713-20.

6 Allied Dunbar, Health Education Authority, Sports Council. Allied Dunbar national fimess survey: a report on activity patterns and fitness levels. Main findings and summary document. London: vey: a report on activity patterns and fitness levels. Main find

7 Stephens T, Caspersen CJ. The demography of physical activity. In: Bouchard C, Shephard RJ, Stephens T, eds. Physical activity, fitness, and health: international proceedings and consensus state-
Ste ment. Champaign, IL: Human Kinetics, 1994:204-13.

8 Powell KE, Blair SN. The public health burdens of sedentary living habits: theoretical but realistic estimates. Med Sci Spors Exerc 1994;26:851-56.
}

retirement status, and other factors. Therefore, promotional efforts will need to be specifically targeted.

In spite of these and other barriers, a more active population is possible. The gradual decline in cigarette smoking and blood cholesterol values in the United States indicates that widespread behavioural change can be achieved. In addition, researchers are learning more about what makes individuals decide to be more active ${ }^{14}$ and are refining guidelines to help practitioners shape and target their counselling. ${ }^{15}$ Finally, people are more likely to stick with an activity they enjoy, ${ }^{16}$ and activities of moderate and vigorous intensity offer a wider range of enjoyable options than vigorous activity alone. As a result, an active life will be less miserable not only because it is healthier but because the activities are fun.

KENNETH E POWELL Associate director for science

Division of Violence Prevention,

National Center for Injury Prevention and Control,

Centers for Disease Control and Prevention,

Atlanta, GA 30333

USA

MICHAEL PRATT

Chief, Physical Activity Branch

Division of Nutrition and Physical Activity,

National Center for Chronic Disease Prevention and Health Promotion,

Centers for Disease Control and Prevention,

Atlanta, GA 30333 ,

USA

9 NIH Consensus Conference. Physical activity and health. NIH Consensus Development Pane on Physical Activity and Cardiovascular Health. IAMA 1996;267:241-6.

10 Caspersen CJ, Powell KE, Christenson GM. Physical activity, exercise, and physical fitness: Definitions and distinctions for health-related research. Public Health Rep 1985;100:126-131.

11 Blair SN, Powell KE, Bazzarre RI, Early IL, Epstein LH, Green LW, et al. Physical inactivity. Workshop V. AHA Prevention Conference III. Behavior change and compliance: keys to improving cardiovascular health. Circulation 1993;88:1402-5.

12 Physical Activity Task Force. More people, more active, more often: physical activity in England. London: Department of Health, June 95.

13 Vouri IM. Sudden death and exercise: effects of age and type of activity. Sport Science Review 1995;4:46-84.

14 Marcus BH, Simkin LR. The transtheoretical model: applications to exercise behavior. Med Sci Sports Exerc 1994;26:1400-4.

15 Calfus KJ, Long PJ, Sallis JF, Wooten WJ, Pratt M, Patrick K. A controlled trial of physician counseling to promote adoption of physical activity. Preventive Medicine (in press).

16 King AC, Blair SN, Bild D, Dishman RK, Dubbert PM, Marcus BH, et al. Determinants of physical activity and interventions in adults. Med Sci Sports Exerc 1992;24(No 6 suppl):S221-

\section{A primary care market?}

\section{May bring benefits but needs thorough evaluation}

It is a fact universally acknowledged that primary care is one of the great strengths of the British health care system. The NHS reforms initiated by Margaret Thatcher in 1989 have shifted the balance of power towards primary care and resulted in more services being provided by general practitioners and colleagues in primary care. This in turn has led to the emergence of new kinds of primary care organisation. These include fundholding practices, multifunds, total purchasing projects, commissioning groups, and out of hours cooperatives. The formation of these organisations is beginning to break down professional isolation among general practitioners and is creating opportunities for greater collaboration. Paradoxically, it is also opening up the prospect of increased competition between primary care providers.

Of particular importance in this context is the establishment of unified health authorities in England and Wales in April 1996 and the responsibility given to these health authorities to promote the government's policy of a primary care led NHS. There is already evidence that those heading the new authorities are keen to move beyond the traditional model of general practitioners working through partnerships to deliver a standard range of general medical services. For example, some authorities have negotiated agreements with practices to offer a wider range of services and have diverted money from hospital and community health services budgets for this purpose. ${ }^{1}$

At the same time, other authorities have encouraged the setting up of total purchasing pilots in which fundholders take responsibility for buying the full range of services for patients. In the case of the Bromsgrove total purchasing project, for example, this includes establishing a "hospital at home" scheme, increasing the use of a general practitioner ward at a community hospital, and contracting for the use of nursing home beds instead of using acute hospitals to provide respite care for patients (C Heath, personal communication).

NHS trusts are also promoting innovations in primary care. The City Health NHS Trust in Newcastle is employing general practitioners to provide general medical services on a salaried basis and is managing their practice staff. Elsewhere, many community trusts are working closely with general practitioners to integrate more effectively the work of primary care 